\title{
Shiro Ikegawa \\ Genetic analysis of skeletal dysplasia: recent advances and perspectives in the post-genome-sequence era
}

Received: 30 January 2006/ Accepted: 6 March 2006/Published online: 3 May 2006

(C) The Japan Society of Human Genetics and Springer-Verlag 2006

\begin{abstract}
Skeletal dysplasia is a group of disorders of the skeleton that result from derangement of growth, development and/or differentiation of the skeleton. Nearly 300 disorders are included; most of them are monogenic diseases. Responsible genes for skeletal dysplasia have been identified in more than 150 diseases mainly through positional cloning. Identification of disease genes would improve patient care through genetic diagnosis as well as improving our understanding of the diseases and molecular mechanism of skeletal tissue formation. Studies of skeletal dysplasia would also help identify disease genes for common diseases affecting bones and joints. In this study, the author reviews recent advances and the current status of the genetic analysis of skeletal dysplasia and its impacts on research into skeletal biology.
\end{abstract}

Keywords Skeletal dylplasia - Classification · Mutation · Disease gene · Genetic diagnosis · Pseudoachondroplasia $\cdot$ Multiple epiphyseal dysplasia $\cdot$ Dysostosis

\section{What is skeletal dysplasia?}

Skeletal dysplasia is a group of disorders that are characterized by abnormal formation of the skeleton because of intrinsic derangement of the growth, development and/or differentiation. Nearly 300 disorders are included

\section{S. Ikegawa}

Laboratory for Bone and Joint Diseases,

SNP Research Center, RIKEN,

4-6-1 Shirokanedai, Minato-ku,

Tokyo 108-8639, Japan

E-mail: sikegawa@ims.u-tokyo.ac.jp

Tel.: + 81-3-5449-5393

Fax: + 81-3-5449-5393

S. Ikegawa

The Japanese Consortium for Skeletal Dylplasia,

Tokyo, Japan in this entity; most of them are heritable (monogenic) diseases. Most of the diseases in the category are rare, but skeletal dysplasia as an entity is a common disease.

There are two classes of skeletal dysplasia: osteochondrodysplasia and dysostosis. Osteochondrodysplasia results from abnormal growth and development of bone and/or cartilage; the lesions are generalized and progressive. Examples include osteogenesis imperfecta (OMIM 166200, 166210, 166220, 259440 ) and achondroplasia (OMIM 100800). In contrast, dysostosis is the disorder of individual bones, singly (skull, hand, arm, etc.) or in combination (e.g., skull and fingers). The lesions are local and nonprogressive. Poly/syndactyly and craniosynostoses are representative diseases. Previously it was believed that the two were different: osteochondrodysplasia was considered a genetic disorder and dysostosis an accidental derangement during embryonic development, unrelated to genes. However, now we know that both are caused by genetic abnormalities.

\section{Classification of skeletal dysplasia and its significance}

As there are so many diseases in the category, classification is necessary for better understanding of skeletal dysplasia. Therefore, in 1969, an international classification was first invented (McKusick and Scott 1971). There were minor revisions twice, until in 1992, drastic changes were introduced to the classification. In the major revision, the diseases were grouped according to radiographic similarities of their phenotypes (Beighton et al. 1992). The grouping is based on the concept of "family" proposed by Spranger (1985). The radiologist tried to group disorders based on presumed pathogenetic similarities with the underlying idea that the phenotypic similarity must reflect the causality. Representative diseases such as achondroplasia and spondylo-epiphyseal dysplasia congenital (SEDC; OMIM 183900) were selected, and diseases with similar radiographic phenotypes were gathered together into groups. This was to prepare for the progress of basic 
research; at the dawn of genome era, the radiologist must have recognized the importance of phenotyping. There are 33 groups for osteochondrodysplasia and three groups for dysostosis in the current classification (Hall 2002).

The grouping by clinical information provided a great deal of help in the basic research, in particular, in identification of disease genes. For example, FGFR3 was first identified as a disease gene for achondroplasia, the prototype of the achondroplasia group (Shiang et al. 1994). Then, disorders in the group were examined for $F G F R 3$, and mutations were found one after another. Similarly, COL2A1 mutation was first found in SEDC (Tiller et al. 1990), and COL2A1 was also found to be the disease gene for other members of the group (Ahmad et al. 1991; Bogaert et al. 1992; Winterpacht et al. 1993; Nishimura et al. 2004; Miyamoto et al. 2005). Thus, a radiologist's insight derived solely from clinical practice supported identification of a number of disease genes at the bench.

\section{Identification of disease genes by clinical information}

Let me review the process of gene identification with achondroplasia, the most common skeletal dysplasia, taken as an example. By linkage analysis, the gene for achondroplasia was the localized to chromosome $4 \mathrm{p}$ (Le Merrer et al. 1994; Velinov et al. 1994). FGFR3 in the region was examined, and a Gly380Arg mutation in its transmembrane domain was found (Shiang et al. 1994). The mutation was so recurrent that chondroplasia was considered to be defined by the single mutation (Bellus et al. 1995a). We examined FGFR3 mutation in an "atypical," milder achondroplasia (Nishimura et al. 1995) and found a mutation in its transmembrane domain; however, it was not Gly380Arg, but Gly375Cys (Ikegawa et al. 1995).

Thus, we know FGFR3 mutations produce similar phenotypes. Then, how about a "similar" disease with a milder phenotype? The second fox is caught in the same snare. Hypochondroplasia (OMIM 146000) is also caused by FGFR3 mutation in the intracellular tyrosine kinase domain (Bellus et al. 1995b). The achondroplasia group contains a similar condition with a more severe phenotype, thanatophoric dysplasia (OMIM 187600, 187610), and the same snare still worked very well. The disorder is also caused by FGFR3 mutations (Tavormina et al. 1995). Furthermore, the list of the achondroplasia group included still other diseases including Crouzon syndrome with acanthosis nigricans (OMIM 100600), SADDAN dysplasia (Francomano et al. 1996), Muenke syndrome (OMIM 602849) and Saethre-Chotzen syndrome (OMIM 101400). The radiologist's prediction was right. All these similar phenotypes are caused by the FGFR3 mutation.

With the help of such clinical information, more than 150 disease genes have been found to date. The list is updated almost weekly. We are in the middle of the cloning rush. The speed of cloning of the disease genes will surely be accelerated further by the recent progress in genome analyses and by establishment of a worldwide database for human DNA sequences.

\section{Genetic diagnosis of skeletal dysplasia}

If you find a disease gene, you can make genetic diagnosis. We have a strong need for genetic diagnosis of skeletal dysplasia because there are so many diseases with complex phenotypes and many individual variations according to age, treatment and environment. No powerful diagnostic tools and reliable biochemical markers are currently available. Current diagnosis largely depends on radiographic examinations, which are very subjective and often error-prone. For example, pseudoachondroplasia (PSACH; OMIM 177170) resembles achondroplasia, as its name shows (Fig. 1a). Both disorders present short-limbed short stature and limb deformity. Diagnosis of PSACH is easy before skeletal maturity because of a characteristic radiographic feature, the "anterior tongue-like protrusion" (Fig. 1b). However, it is a disease of the skeleton. Skeletal features change with age (Fig. 1c): after the skeleton reaches maturity, the pathognomonic feature disappears (Fig. 1d), and with age, secondary changes such as osteoarthritis (OA) and fractures make the diagnosis very difficult.

Let me show the current status and problems of genetic diagnosis using PSACH as an example. Its disease gene is cartilage oligomeric matrix protein (COMP; Hecht et al. 1995), which encodes an extracellular matrix protein specific to cartilage. The COMP protein has characteristic motifs including calmodulin-like repeat (CLR). COMP mutations are also found in multiple epiphyseal dysplasia (MED; OMIM 601560; Briggs et al. 1995), which is not similar to PSACH at first glance. The clinical abnormalities of PSACH are severe. The adult height is sometimes below $1 \mathrm{~m}$. Radiographic abnormalities are seen in the spine, epiphyses and metaphyses. In contrast, MED is a mild dysplasia. Many patients are of normal height. Radiographic abnormalities are limited to epiphyses with little or no spinal involvement (Haga et al. 1998).

They look apparently different, but are the same in essence. Transitional cases have been known (Hall and Dorst 1969). Therefore, they have been grouped together in the international classification, and molecular studies confirmed that they are nothing but a part of the continuous spectrum of the COMP mutation (Unger and Hecht 2001). The mildest end of the spectrum may be common idiopathic OA. We have experienced a family with mild dysplasia harboring a COMP mutation that was diagnosed as having familial OA (Kawaji et al. 2002).

To clarify the spectrum of the COMP mutation and its phenotypes, we examined the COMP mutation in 35 consecutive Japanese patients (Itoh et al., unpublished). 

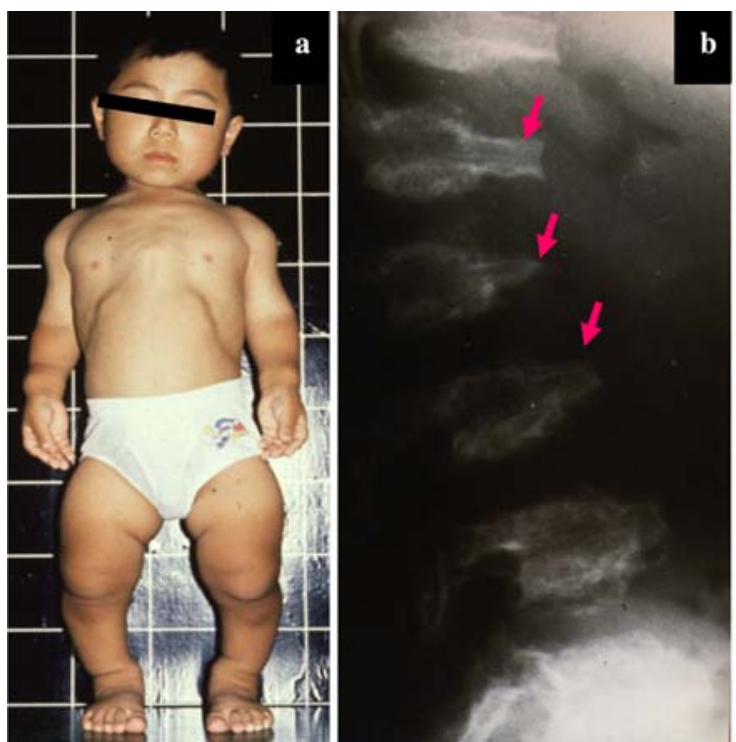

Fig. 1a-d Skeletal features change with age. a A pseudoachondroplasia patient aged 6. Short-limbed short stature resembling achondroplasia, but the patient is of normal facies. b Lateral radiograph of the spine aged 6 showing the "anterior tongue-like

Detection rate of the COMP mutation is very high in cases with clinical diagnosis of PSACH. Mutations are clustered in CLRs, especially in the seventh CLR (Ikegawa et al. 1998a, b). Then, we examined genotypephenotype association and found correlation between the position of COMP mutations and the severity of short stature. Mutations in seventh CLR cause extremely severe short stature, while mutations elsewhere show relatively mild phenotype (Mabuchi et al. 2003). In contrast to PSACH, COMP mutation is found in only $1 / 5$ of MED patients. This is due to genetic heterogeneity in MED. Five other genes have already been recognized: for the dominant-type MED, COL9A1-A3 encoding $\alpha 1-3$ (IX) chains of type IX collagen (Muragaki et al. 1996; Paassilta et al. 1999; Czarny-Ratajczak et al. 2001), respectively, and MATN3 encoding matrilin 3 (Chapman et al. 2001); and for the recessive-type MED, DTDST encoding diastrophic dysplasia-sulfate transporter (Superti-Furga et al. 1999). As there are many MED genes, genetic diagnosis is difficult and inefficient.

If we could differentiate them a priori, we would be able to reduce time and labor so much. The hint was in pathology. Chondrocytes from COMP diseases have intracellular inclusion bodies (Stanescu et al. 1992). This is the enlarged rough-surfaced endoplasmic reticulum containing COMP. We hypothesized that the COMP mutation impairs the protein's secretion into the cartilage matrix, and we tested whether COMP in blood is decreased in the patients. Plasma COMP level is decreased in patients with COMP mutation, indicating that we can screen the presence of COMP mutations by a blood test (Mabuchi et al. 2004b).

MATN3 mutation is the most common MED mutation in Japanese (Mabuchi et al. 2004a). Mutations are

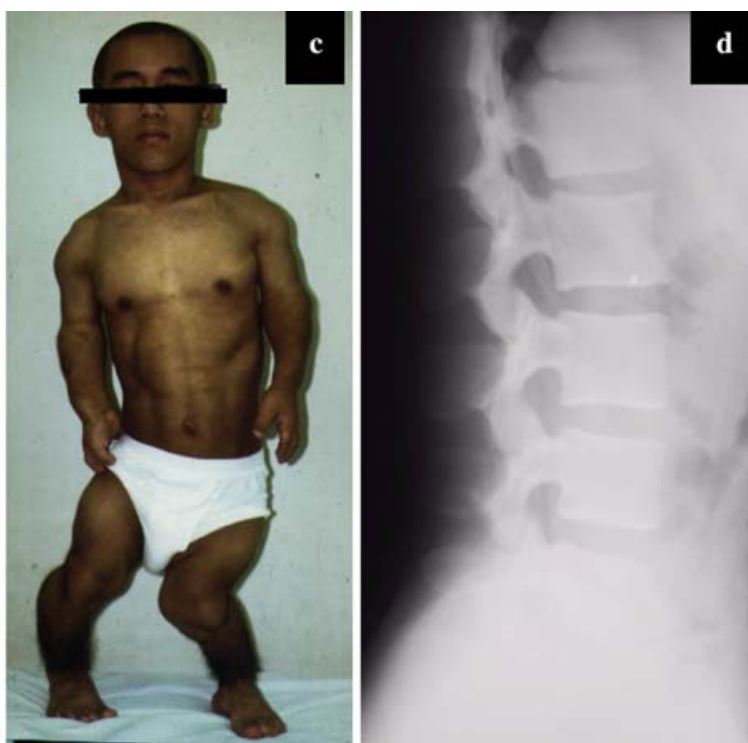

protrusion" appearance (red arrow). c The same patient aged 17 The short stature and deformity of extremities have become more conspicuous. d Lateral radiograph of the spine aged 17. The characteristic feature has disappeared

clustered in the von Willebrand factor type A domain, suggesting the importance of this region in vivo. Type IX collagen mutations are not common in Japanese MED. Interestingly, all type IX collagen mutations result in loss of the third collagenous domains by skipping of a single exon. Previous studies reported that doublelayered patella is specific to DTDST mutation; however, we found it in a case with type IX collagen mutation (Nakashima et al. 2005). Systematic examination by integration of such clinical and genetic information en-
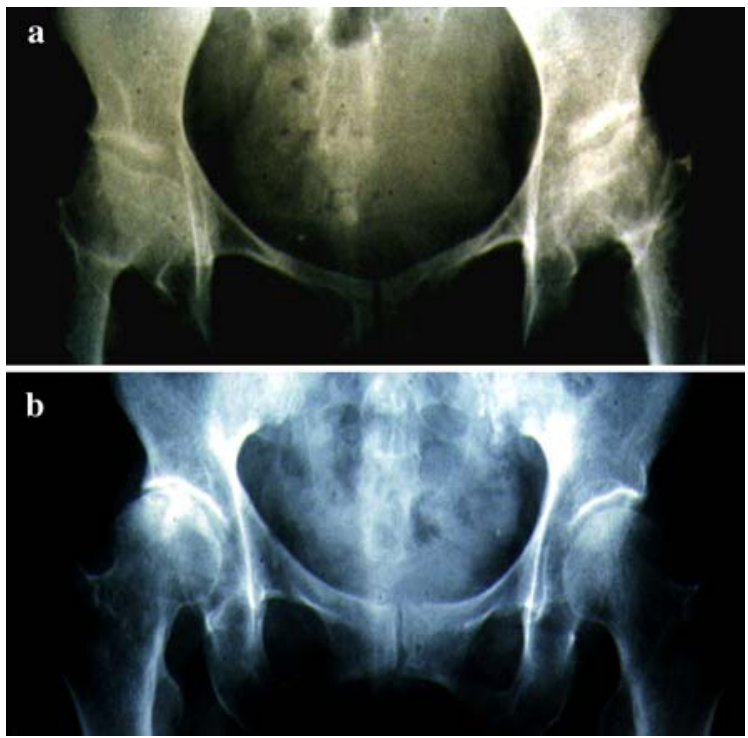

Fig. 2a, b Radiographs of hip osteoarthritis (OA). a Multiple epiphyseal dysplasia (MED). Severe, early-onset OA at the age of 30. b Common idiopathic OA at the age of 66 
ables the efficient genetic diagnosis of MED. Of course, further identification of unknown MED genes is necessary for this system. Known gene mutations were found in fewer than half of the MED patients (Jackson et al. 2004; Jakkula et al. 2005). Familial cases not linked to known MED loci exist (Jakkula et al. 2005; our unpublished experience).

\section{Identification of disease genes}

We have to identify the disease genes in order to make genetic diagnosis possible. Due to the Human Genome Project, the task has become much easier. To identify the genes, integration of clinical and genetic information is important, also. Before the Project, there were so many steps that were all time and labor consuming. Even after the gene to be examined was determined, there remained so many tasks, including determination of sequences of cDNA and genomic DNA, determination of gene structures, construction of the mutation detection system, designing of PCR, determination of sequence of patients and exclusion of polymorphisms. In the post-genome-sequence era, most of the tasks have disappeared; a huge amount of information is available. After you determine the candidate gene, all you have to do is check the DNA sequence of the patients.

If you successfully integrate clinical and genetic information, identification of disease genes is easy. The best example is the identification of the gene for metaphyseal chondrodysplasia, Schmid type (OMIM 156500; Warman et al. 1993), followed by that for spondylometaphyseal chondrodysplasia, Japanese type (Hasegawa et al. 1994; Ikegawa et al. 1998a, b). Furthermore, by integration of information on humans and mice, we can speed up the identification of disease genes. Linkage in humans can not narrow down the critical region, but we can do it in mice because we can freely enlarge the family in mice. The comparative genomics approach including synteny mapping could further localize the gene. Phenotyping of mice is difficult, but in humans a huge list of phenotypes are collected in the medical record. Many probands are available in human. Thus, the integrated approach could make gene identification and subsequent functional analysis much easier.

\section{Advances in classification}

Based on the genetic information, reclassification of skeletal dysplasia is rapidly progressing. The most significant progress is found in the group of lethal skeletal dysplasias. Previously, the spondylodysplastic and other perinatally lethal group consisted of achondrogenesis type 1A (OMIM 200600) and lethal platyspondylic skeletal dysplasias (LPSD). Four subtypes of the LPSD group are known: thanatophoric dysplasia, and LPSDs, San Diego type (OMIM 270230), Torrance type (OMIM
Table 1 Skeletal dysplasias and their disease genes associated with osteoarthritis

\begin{tabular}{ll}
\hline Skeletal dysplasia & Disease gene (gene symbol) \\
\hline SED congenita & COL2A1 \\
SED tarda & COL2A1, SEDL \\
Stickler dysplasia & COL2A1,COL11A1-A2 \\
Pseudoachondroplasia & COMP \\
MED & COMP,COL9A1-A3, MATN3, DTDST \\
PPRC & WISP3
\end{tabular}

$S E D$ Spondyloepiphyseal dysplasia, $M E D$ multiple epiphyseal dysplasia, $P P R C$ progressive pseudorheumatoid chondrodysplasia

151210), and Luton type (OMIM 151210). FGFR3 mutations were found first in thanatophoric dysplasia (Tavormina et al. 1995) and then in LPSD, San Diego type (Brodie et al. 1999), transferring them to the achondroplasia group. Accumulation of cases and the presence of intermediate forms of LPSD, Torrance and Luton types, indicated that they are an identical entity and their phenotypes are reminiscent of severe forms of SEDC. Therefore, we examined the COL2A1 mutation in LPSD, Torrance type, and found mutations specifically in its C-terminal region (Nishimura et al. 2004). LPSD, Torrance and Luton types, will be moved to the SEDC group. Classification based on molecular pathogenesis, such as "type II collagenopathy" and "type X collagenopathy," has already been included in the current classification (Hall 2002), and this trend will continue in the future classification.

\section{Significance of genetic research for skeletal dysplasia}

The genetic study of skeletal dysplasia helps us to provide better care and treatment for patients who are suffering from this disabling condition. In addition, through its study, we can approach the molecular mechanism of the skeletal formation of humans because all the disease genes are associated with skeletal formation in human. The list of the disease genes includes a huge variety of molecules including extracellular matrix proteins, enzymes, hormones, cytokines and their receptors, and transcription factors. The variety reflects the complexity of skeletal formation in vivo. Using the human disease genes as starting points, we can clarify the complex mechanism. Best examples are $S O X 9$ for campomelic dysplasia (Foster et al. 1994) and CBFA1/ $R U N X 2$ for cleidoclanial dysplasia (Otto et al. 1997).

Furthermore, skeletal dysplasias are genetic models for common bone and joint diseases, including OA, osteoporosis, rheumatoid arthritis, scoliosis and disc herniation. For example, there are many skeletal dysplasias associated with OA (Table 1). These diseases are nothing but severe, early onset, hereditary forms of OA (Fig. 2). Their disease genes are being identified, and are all good candidate genes for common idiopathic OA. 
The study of the rare monogenic diseases can bring a breakthrough for clarifying the genetic aspects of common diseases.

Thus, as regards medicine and basic science, research into skeletal dysplasia will give us a lot of knowledge. Integration of clinical and genetic information is the key to success for research in the genome era.

Acknowledgements We thank patients, families and members of the Japanese Consortium for Skeletal Dysplasia for help in performing the study. This work was supported by Grants-in-aid for Research on Child Health and Development (Contract grant No: 17C-1) and from the Ministry of Education, Culture, Sports and Science of Japan (Contract grant No: 17209050).

\section{References}

Ahmad NN, Ala-Kokko L, Knowlton RG, Jimenez SA, Weaver EJ, Maguire JI, Tasman W, Prockop DJ (1991) Stop codon in the procollagen II gene (COL2A1) in a family with the Stickler syndrome (arthro-ophthalmopathy). Proc Natl Acad Sci USA 88:6624-6627

Beighton P, Giedion ZA, Gorlin R, Hall J, Horton B, Kozlowski K, Lachman R, Langer LO, Maroteaux P, Poznanski A, et al (1992) International classification of osteochondrodysplasias. International Working Group on Constitutional Diseases of Bone. Am J Med Genet 42:223-229

Bellus GA, Hefferon TW, Ortiz de Luna RI, Hecht JT, Horton WA, Machado M, Kaitila I, McIntosh I, Francomano CA (1995a) Achondroplasia is defined by recurrent G380R mutations of FGFR3. Am J Hum Genet 56:368-373

Bellus GA, McIntosh I, Smith EA, Aylsworth AS, Kaitila I, Horton WA, Greenhaw GA, Hecht JT, Francomano CA (1995b) A recurrent mutation in the tyrosine kinase domain of fibroblast growth factor receptor 3 causes hypochondroplasia. Nat Genet 10:357-359

Bogaert R, Tiller GE, Weis MA, Gruber HE, Rimoin DL, Cohn DH, Eyre DR (1992) An amino acid substitution (Gly853 $\rightarrow$ Glu) in the collagen alpha $1(\mathrm{II})$ chain produces hypochondrogenesis. J Biol Chem 267:22522-22526

Briggs MD, Hoffman SMG, King LM, Olsen AS, Mohrenweiser H, Leroy JG, Mortier GR, Rimoin DL, Lachman RS, Gaines ES, Cekleniak JA, Knowlton RG, Cohn DH (1995) Pseudoachondroplasia and multiple epiphyseal dysplasia due to mutations in the cartilage oligomeric matrix protein gene. Nat Genet 10:330-335

Brodie SG, Kitoh H, Lachman RS, Nolasco LM, Mekikian PB, Wilcox WR (1999) Platyspondylic lethal skeletal dysplasia, San Diego type, is caused by FGFR3 mutations. Am J Med Genet 84: 476-480

Chapman KL, Mortier GR, Chapman K, Loughlin J, Grant ME, Briggs MD (2001) Mutations in the region encoding the von Willebrand factor A domain of matrilin-3 are associated with multiple epiphyseal dysplasia. Nat Genet 28:393-396

Czarny-Ratajczak M, Lohiniva J, Rogala P, Kozlowski K, Perala M, Carter L, Spector TD, Kolodziej L, Seppanen U, Glazar R, Krolewski J, Latos-Bielenska A, Ala-Kokko L (2001) A mutation in COL9A1 causes multiple epiphyseal dysplasia: further evidence for locus heterogeneity. Am J Hum Genet 69:969-980

Foster JW, Dominguez-Steglich MA, Guioli S, Kowk G, Weller PA, Stevanovic M, Weissenbach J, Mansour S, Young ID, Goodfellow PN, et al (1994) Campomelic dysplasia and autosomal sex reversal caused by mutations in an SRY-related gene. Nature 372:525-530

Francomano CA, Bellus GA, Szabo J, McIntosh I, Dorst J, Lee R, Hurko O, Fraley AE, Bamshad MJ (1996) A new skeletal dysplasia with severe tibial bowing, profound developmental delay and acanthosis nigricans is caused by a Lys 650 Met mutation in fibroblast growth factor receptor 3 (FGFR3). Am J Hum Genet 59 (Suppl, Abstract):A25

Haga N, Nakamura K, Takikawa K, Manabe N, Ikegawa S, Kimizuka M (1998) Stature and severity in multiple epiphyseal dysplasia. J Pediatr Orthop 18: 394-397

Hall CM (2002) International nosology and classification of constitutional disorders of bone. Am J Med Genet 113:65-77

Hall JE, Dorst JP (1969) Pseudoachondroplastic SED, recessive Maroteaux-Lamy type. The clinical delineation of birth defects. Birth Defects Orig Art Ser 5:242-257

Hasegawa T, Kozlowski K, Nishimura G, Hara H, Hasegawa Y, Aso T, Koto S, Nagai T, Tsuchiya Y (1994) Japanese type of spondylo-metaphyseal dysplasia. Pediatr Radiol 24:194-197

Hecht JT, Nelson LD, Crowder E, Wang Y, Elder FFB, Harrison WR, Francomano CA, Prange CK, Lennon GG, Deere M, Lawler J (1995) Mutations in exon 17B of cartilage oligomeric matrix protein (COMP) cause pseudoachondroplasia. Nat Genet 10:325-329

Ikegawa S, Fukushima Y, Isomura M, Takada F, Nakamura Y (1995) Mutation of fibroblast growth factor receptor-3 in six sporadic and one familial Japanese cases with achondroplasia. Hum Genet 96:309-311

Ikegawa S, Nishimura G, Nagai T, Hasegawa T, Ohashi $H$, Nakamura Y (1998a) Mutation of the type X collagen gene (COL10A1) causes spondylometaphyseal dysplasia. Am J Hum Genet 63:1659-1662

Ikegawa S, Ohashi H, Nishimura G, Kim KC, Sannohe A, Kimizuka M, Fukushima Y, Nagai T, Nakamura Y (1998b) Novel and recurrent COMP (cartilage oligomeric matrix protein) mutations in pseudoachondroplasia and multiple epiphyseal dysplasia. Hum Genet 103:633-638

Jackson GC, Barker FS, Jakkula E, Czarny-Ratajczak M, Makitie O, Cole WG, Wright MJ, Smithson SF, Suri M, Rogala P, Mortier GR, Baldock C, Wallace A, Elles R, Ala-Kokko L, Briggs MD (2004) Missense mutations in the beta strands of the single A-domain of matrilin-3 result in multiple epiphyseal dysplasia. J Med Genet 41:52-59

Jakkula E, Makitie O, Czarny-Ratacjzak M, Jackson GC, Damignani R, Susic M, Briggs MD, Cole WG, Ala-Kokko L (2005) Mutations in the known genes are not the major cause of MED; distinctive phenotypic entities among patients with no identified mutations. Eur J Hum Genet 13:292-301

Kawaji H, Nishimura G, Watanabe S, Mabuchi A, Ikeda T, Ohashi H, Sasaki A, Sano T, Ikegawa S (2002) Autosomal dominant precocious osteoarthropathy due to a mutation of the cartilage oligomeric matrix protein (COMP) gene: further expansion of the phenotypic variations of COMP defects. Skeletal Radiol 31:730-737

Le Merrer M, Rousseau F, Legeai-Mallet L, Landais JC, Pelet A, Bonaventure J, Sanak M, Weissenbach J, Stoll C, Munnich A, Maroteaux P (1994) A gene for achondroplasia-hypochondroplasia maps to chromosome 4p. Nat Genet 6:318-321

Mabuchi A, Ikeda T, Fukuda A, Koshizuka Y, Hiraoka H, Miyoshi K, Haga N, Kawaguchi H, Kawakami A, Yamamoto S, Takatori Y, Nakamura K, Ikegawa S (2001) Identification of sequence polymorphisms of the COMP (cartilage oligomeric matrix protein) gene and association study in osteoarthrosis of the knee and hip joints. J Hum Genet 46:456-462

Mabuchi A, Manabe N, Haga N, Kitoh H, Ikeda T, Kawaji H, Tamai K, Hamada J, Nakamura S, Brunetti-Pierri N, Kimizuka M, Takatori Y, Nakamura K, Nishimura G, Ohashi H, Ikegawa S (2003) Novel types of COMP mutations and genotype-phenotype association in pseudoachondroplasia and multiple epiphyseal dysplasia. Hum Genet 112:84-90

Mabuchi A, Haga N, Maeda K, Nakashima E, Manabe N, Hiraoka H, Kitoh H, Kosaki R, Nishimura G, Ohashi H, Ikegawa $S$ (2004a) Novel and recurrent mutations clustered in the von Willebrand factor A domain of MATN3 in multiple epiphyseal dysplasia. Hum Mutat 24:439-440

Mabuchi A, Momohara S, Haga N, Ohashi H, Takatori Y, Nishimura G, Ikegawa S (2004b) Circulating COMP is 
decreased in pseudoachondroplasia and multiple epiphyseal dysplasia patients carrying COMP mutations. Am J Med Genet 129A:35-38

McKusick VA, Scott CI (1971) A nomenclature for constitutional disorders of bone. J Bone Joint Surg (Am) 53:978-986

Miyamoto Y, Nakashima E, Hiraoka H, Ohashi H, Ikegawa S (2005) A type II collagen mutation also results in oto-spondylomegaepiphyseal dysplasia. Hum Genet 118:175-178

Muragaki Y, Mariman ECM, van Beersum SEC, Perala M, van Mourik JBA, Warman ML, Olsen BR, Hamel BCJ (1996) A mutation in the gene encoding the alpha-2 chain of the fibrilassociated collagen IX, COL9A2, causes multiple epiphyseal dysplasia (EDM2). Nat Genet 12:103-105

Nakashima E, Kitoh H, Maeda K, Haga N, Kosaki R, Mabuchi A, Nishimura G, Ohashi H, Ikegawa S (2005) Novel COL9A3 mutation in a family with multiple epiphyseal dysplasia. Am J Med Genet 132A:181-184

Nishimura G, Fukushima Y, Ohashi H, Ikegawa S (1995) Atypical radiological findings in achondroplasia with uncommon mutation of the fibroblast growth factor receptor-3 (FGFR-3) gene. Am J Med Genet 59:393-395

Nishimura G, Nakashima E, Mabuchi A, Shimamoto K, Shimamoto T, Shimao Y, Nagai T, Yamaguchi T, Kosaki R, Ohashi H, Makita Y, Ikegawa S (2004) Identification of COL2A1 mutations in platyspondylic skeletal dysplasia, Torrance type. J Med Genet 41:75-79

Nishimura G, Haga N, Kitoh H, Tanaka Y, Sonoda T, Kitamura M, Shirahama S, Itoh T, Nakashima E, Ohashi H, Ikegawa S (2005) The phenotypic spectrum of COL2A1 mutations. Hum Mutat 26:36-43

Otto F, Thornell AP, Crompton T, Denzel A, Gilmour KC, Rosewell IR, Stamp GW, Beddington RS, Mundlos S, Olsen BR, Selby PB, Owen MJ (1997) Cbfal, a candidate gene for cleidocranial dysplasia syndrome, is essential for osteoblast differentiation and bone development. Cell 89:765-771

Paassilta P, Lohiniva J, Annunen S, Bonaventure J, Le Merrer M, Pai L, Ala-Kokko L (1999) COL9A3: a third locus for multiple epiphyseal dysplasia. Am J Hum Genet 64:10361044
Shiang R, Thompson LM, Zhu YZ, Church DM, Fielder TJ, Bocian M, Winokur ST, Wasmuth JJ (1994) Mutations in the transmembrane domain of FGFR3 cause the most common genetic form of dwarfism, achondroplasia. Cell 78:335-342

Spranger J (1985) Pattern recognition in bone dysplasias. Prog Clin Biol Res 200:315-342

Stanescu R, Stanescu V, Muriel MP, Maroteaux P (1992) Multiple epiphyseal dysplasia, Fairbank type: morphologic and biochemical study of cartilage. Am J Med Genet 45:501-507

Superti-Furga A, Neumann L, Riebel T, Eich G, Steinmann B, Spranger J, Kunze J (1999) Recessively inherited multiple epiphyseal dysplasia with normal stature, club foot, and double layered patella caused by a DTDST mutation. J Med Genet 36:621-624

Tavormina PL, Shiang R, Thompson LM, Zhu YZ, Wilkin DJ, Lachman RS, Wilcox WR, Rimoin DL, Cohn DH, Wasmuth JJ (1995) Thanatophoric dysplasia (types I and II) caused by distinct mutations in fibroblast growth factor receptor 3. Nat Genet 9:321-328

Tiller GE, Rimoin DL, Murray LW, Cohn DH (1990) Tandem duplication within a type II collagen gene (COL2A1) exon in an individual with spondyloepiphyseal dysplasia. Proc Natl Acad Sci USA 87:3889-3893

Unger S, Hecht JT (2001) Pseudoachondroplasia and multiple epiphyseal dysplasia: new etiologic developments. Am J Med Genet 106:244-250

Velinov M, Slaugenhaupt SA, Stoilov I, Scott CI Jr, Gusella JF, Tsipouras P (1994) The gene for achondroplasia maps to the telomeric region of chromosome $4 \mathrm{p}$. Nat Genet 6:314-317

Warman ML, Abbott M, Apte SS, Hefferon T, McIntosh I, Cohn DH, Hecht JT, Olsen BR, Francomano CA (1993) A type X collagen mutation causes Schmid metaphyseal chondrodysplasia. Nat Genet 5:79-82

Winterpacht A, Hilbert M, Schwarze U, Mundlos S, Spranger J, Zabel BU (1993) Kniest and Stickler dysplasia phenotypes caused by collagen type II gene (COL2A1) defect. Nat Genet 3:323-326 